AD WATCH

\title{
Tobacco promotion in Central and Eastern Europe
}

$-6$

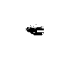

$+\infty$

$-$

$+$

$+$

s.

3

$+$

6

$+2$

4

;.

4

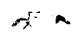

5

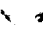

4

Send original examples of material for Ad Watch to Simon Chapman at the address given on the inside front cover
Eastern Europe represents an important potential market for the tobacco industry. According to the Food and Drug Organisation, tobacco consumption from 1974 to 1986 rose by $1.2 \%$ in this part of the world, compared with a decrease of $1.1 \%$ in the United States and $0.7 \%$ in Western Europe.

The tobacco industry is well aware of this potential and has wasted no time since the fall of the Iron Curtain in imposing itself in Eastern Europe. On a visit to Prague in August 1992 I photographed these "Camel" and "Marlboro" trams circulating throughout the city. According to World Tobacco (July 1992), a similar "Camel" tram is also circulating in Moscow. In addition to the decorated trams, there were a large number of billboard advertisements for Marlboro and Camel, many without any health warnings. I believe that this situation is common to most of Central and Eastern Europe, especially as the tobacco industry's aggressive promotion campaigns are relatively little hindered by legislation in these countries, which is weak, vague, or nonexistent.

There is currently complete confusion in the Czech and Slovak Republics about legislation on tobacco advertising (see also Tobacco Alert, April 1992, p 12). Article 3 of Act 37 of the Czech National Council of 28 March 1989 stipulates that it is forbidden to promote the consumption of alcohol, other additive substances, or smoking in the press or other communication media. In practice, however, the authorities of the Czech Republic are interpreting "smoking" very narrowly, so that the law prohibits only advertisements that show pictures of people with lit cigarettes in their mouths. As the public in countries where tobacco advertising is permitted knows only
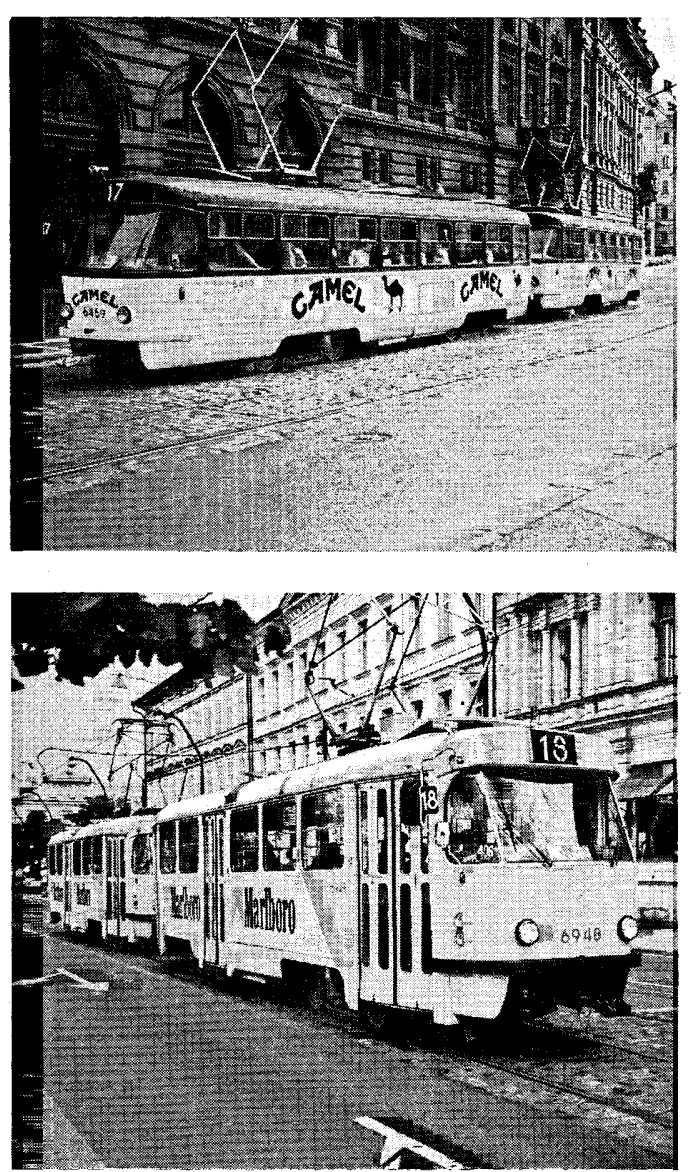

too well, a broad range of powerful tobacco advertising imagery is possible without ever showing a person actually smoking.

LUK JOOSSENS CATHERINE HOWIE

European Bureau for Action on Smoking Prevention, Brussels, Belgium 